\section{Bullying in schools}

\section{Author's reply}

EDrroR,-I agree with Vidya Rao that schools should be encouraged to tackle bullying.' In my clinical experience, however, parents have not necessarily already taken the matter up with the school. Many parents have not even known that their child was being bullied, and those who have approached the school have often had the response, "We don't have bullying in this school."

Schools can do much to reduce bullying. In Norway a national campaign was mounted after three children committed suicide as a result of bullying. A number of measures at the school, class, and individual levels were used. The frequency of bully-victim problems decreased by half during the following two years. ${ }^{2}$ Rates of truancy and antisocial behaviours in general also dropped, and pupils' satisfaction with school life improved. In Britain the Department of Education's Sheffield bullying project evaluated a similar intervention programme. The results of this were published last year, ${ }^{3}$ together with clear practical advice for teachers. ${ }^{4}$ This research provided the basis for the Department for Education's guidelines.'

In my editorial I hoped to raise doctors' awareness of bullying, its effects on the child, and what can be done in the hope that together doctors, parents, and schools can prevent the continued abuse of victims of bullying in schools. ${ }^{6}$

JUDITH DAWKINS

Department of Mental Health Sciences,

St George's Hospital Medical School,

London SW17 ORE

1 Rao V. Bullying in schools. BMf 1995;310:1065-6. (22 April.)

2 Olweus D. Bully/victim problems among schoolchildren: basic facts and effects of a school based intervention program. In: Pepler D, Rubin K, eds. The development and treatment of childhood aggression. Hillsdale, NJ: Erlbaum, 1991.

3 Smith PK, Sharp S. School bullying: insights and perspectives. London: Routledge, 1994.

4 Sharp S, Smith PK. Tackling bullying in your school: a practical handbook for teachers. London: Routledge, 1994.

5 Department for Education. Bullying: don't suffer in silence-an anti-bullying pack for schools. London: HMSO, 1994.

6 Dawkins J. Bullying in schools: doctors' responsibilities. BMF 1995;310:274-5. (4 February.)

\section{Smoking and death}

EDIToR,-The Nazi ideology and movement were more effective with regard to eugenics than with regard to external threats to health.' Statistics on cigarette production between 1932 and 1944 show an upward trend and an increase of $100 \%$ (figure $)^{2}$ : The peak was reached in 1940 and can be compared with the 130 billion cigarettes consumed in Germany today. ${ }^{3}$ The firm Reemtsma controlled $80 \%$ of the market at that time, and the early attacks of the SA (Sturmabteilung) movement

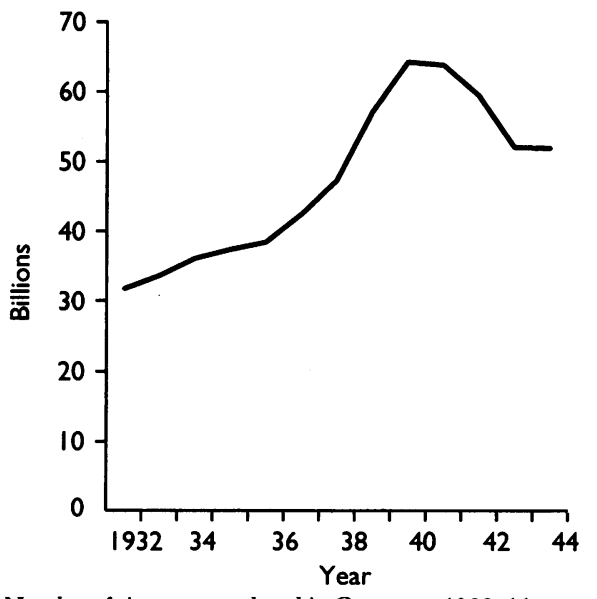

Number of cigarettes produced in Germany, 1932-44 against the firm were counteracted by a DM10m donation via Goering to the Adolf Hitler fund. ${ }^{2}$

The popularity of the antismoking coalition within the Nazi movement $t^{4}$ came to an end with the beginning of the second world war. The overriding interests of the morale and fighting capacity of the army meant that free cigarettes for soldiers were a necessity. Like the first world war had been, the second world war was the impetus for a new generation of men and women in Germany, Britain, and the United States to take up smoking. For the Nazis, smoking and drinking were only two of the sources of a degenerative "Volksgesundheit." The Nazis were surely flexible enough not to let their aim of conquering the world be spoiled by antismoking campaigns. In saying that Hitler caused the second world war one has also to say that by this he caused a large part of the smoking epidemic of the ' 50 s in the world. The universal concept of causation counts deaths irrespective of their origin. Smoking does not kill; i poses a risk to your health. Peto overstates his message by comparing 50 million deaths from smoking and Nazism. ${ }^{6}$

DIETER BORGERS Head, department of epidemiolog Landesinstitut für den Offentlichen Gesundheitsdienst, D-33611 Bielefeld,

Germany

1 Peto R. Smoking and death: the past 40 years and the next 40 BMF 1994;309:937-9.

2 Pritzkoleit K. Auf einer Woge von Gold. Munich, Zürich Droemer und Knauer, 1964.

3 Borgers D, Hueck C. Tabakmultis und Gesundheitspolitik. In fahrbuch fur kritische Medizin 8. Berlin: Argument, 1982.

4 Smith DA, Ströbele SA, Egger M. Smoking and health promotio in Nazi Germany. $\mathcal{F}$ Epidemiol Community Health 1994;48: 220-3.

5 Smith GD, Ströbele S, Egger M. Smoking and death. $B M F$ 1995;310:396.

6 Peto R. Smoking and death. BMF 1995;310:396.

\section{Babies' deaths linked to suboptimal care}

EDITOR,-When a government report states that over $40 \%$ of deaths during birth are linked to substandard care both those managing labour and those purchasing maternity care wish to know how practice can be changed to reduce the number of such deaths.' Changes to practice should be based on firm, scientifically based evidence.

The confidential inquiry into stillbirths and deaths in infancy has not set standards for care, "substandard" being decided at a regional level on the basis of individual cases. In contrast, the inquiry into maternal deaths has produced guidelines for good practice. ${ }^{23}$ Therefore, how valid are these estimates of substandard care, and how does one interpet differences among regions as the inquiry has not published interobserver studies? Until criteria for substandard care are set and interregional variation has been assessed it is misleading to publish these data without expressing considerble caution.

The inquiry examines only deaths, and the denominator of intrapartum care that does not result in death is ignored. There can therefore be only a speculative association between substandard care, however defined, and outcome. Before investigating certain factors further one would wish to establish that the level of substandard care in normal labours is different. Case-control studies may overcome such problems, but with the increasing use of obstetric computer databases in maternity care it should be possible to assess the risk associated with substandard care by multivariate analysis, using data from all intrapartum events.

Confidential inquiries may be useful audit tools, although there is no firm evidence of their effectiveness. Inquiries such as the confidential inquiry into stillbirths and deaths in infancy will not improve our knowledge of the antecedents to death unless rigorous epidemiological and clinical research methodologies are used to answer specific objectives.

CHARLES D A WOLFE Clinical director of obstetrics nd gynaecolog

Guy's and St Thomas's Hospitals Trust,

London SE1 7EH

1 Dillner L. Babies' deaths linked to suboptimal care. $B M \mathcal{F}$ 1995;310:757. (25 March.)

2 Confidential inquiry into stillbirths and deaths in infancy. Part one. London: HMSO, 1995.

3 Report on confidential inquiries into maternal deaths in the United Kingdom 1988-1990. London: HMSO, 1994.

\section{Errors in administration of intravenous drugs}

EDITOR,-An audit to identify the type, rate, and potential severity of errors associated with medical and nursing staff administering intravenous drugs was carried out at the Royal Belfast Hospital for Sick Children over a four week period.

The disguised observation technique was used, whereby the observer accompanied the person involved in preparing and giving each dose. ${ }^{1}$ The errors were classified as incorrect administration rate and time $>30$ minutes from the prescribed time) and as incorrect diluent or volume, incorrect administration method (bolus or infusion), dose duplication, and omission. One hundred and seventy nine intravenous doses were observed, 132 given by senior house officers and 47 by nurses.

A total of 291 errors were detected in 168 of the observed doses, of which 237 were by senior house

Number (percentage) of errors in giving intravenous drugs

\begin{tabular}{lccc}
\hline & $\begin{array}{c}\text { Doses given } \\
\text { by senior } \\
\text { house officers } \\
(\mathrm{n}=132)\end{array}$ & $\begin{array}{c}\text { Doses given } \\
\text { by nurses } \\
(\mathrm{n}=47)\end{array}$ & $\begin{array}{c}\text { Total } \\
(\mathrm{n}=179)\end{array}$ \\
Error type & $105(80)$ & $35(74)$ & $140(78)$ \\
Incorrect time & $104(79)^{\star}$ & $10(21)$ & $114(63)$ \\
Incorrect rate & $16(12)$ & $8(17)$ & $24(13)$ \\
Incorrect volume & $1(1)$ & 0 & $1(1)$ \\
Incorrect diluent & $8(6)$ & $1(2)$ & $9(5)$ \\
Incorrect method & $1(1)$ & 0 & $1(1)$ \\
Dose duplication & $2(1)$ & 0 & $2(1)$ \\
Dose omission & 237 & 54 & 291 \\
\hline Total errors & & &
\end{tabular}

$\star \mathrm{P}<0.001$.

officers (table). Of the 132 doses given by senior house officers, $129(98 \%)$ had at least one error, compared with 39 of the 47 doses $(83 \%)$ given by nurses. Forty eight per cent of errors were associated with an incorrect administration time, with only $20 \%$ of the doses given at the correct time by the senior house officers and $26 \%$ by nurses. Nurses gave $79 \%$ of their doses at the recommended rate; only $21 \%$ of the doses given by senior house officers were correct. Fifty five per cent of doses were given in less than 30 seconds (all by senior house officers). Most diluent volume errors occurred when nurses used the intramuscular rather than the intravenous reconstitution volume. Two doses were omitted, one dose was duplicated, and on one occasion the wrong diluent was used for a drug.

Yates corrected $\chi^{2}$ test showed a highly significant $(P=0.0011)$ increased overall error rate when senior house officers administered the intravenous drugs, the major error being an inappropriately fast rate of administration. No potentially lethal or serious errors were observed, and the rate of clinically significant errors as defined by Folli $e t a l^{2}$ was $3.3 \% ; 83 \%$ of these were attributed to senior house officers.

This study shows that errors in intravenous administration of drugs are statistically more likely 